\title{
TENDÊNCIAS DA GESTÃO SOCIAL
}

\section{Ladislau Dowbor}

RESUMO: O que está se tornando evidente, já não numa visão estreita de crítica sistemática anti-capitalista, mas de bom senso econômico e social, é que um sistema que sabe produzir, mas não sabe distribuir, simplesmente não é suficiente. Sobretudo se, ainda por cima, joga milhões no desemprego, dilapida o meioambiente e remunera mais os especuladores do que os produtores. $E$ a construção de alternativas envolve um leque de alianças sociais evidentemente mais amplo do que o conceito de classes redentoras, burguesa para uns, proletária para outros, que dominou o século $X X$. $O$ debate sobre quem tinha razão continuará sem dúvida a alimentar as nossas discussões, mas a realidade é que a própria realidade mudou. O crescimento econômico, quando existe, não é suficiente. Nem a área produtiva, nem as redes de infraestruturas, e nem os serviços de intermediação funcionarão de maneira adequada se não houver investimento no ser humano, na sua formação, na sua saúde, na sua cultura, no seu lazer, na sua informação. Em outros termos, a dimensão social do desenvolvimento deixa de ser um "complemento", uma dimensão humanitária de certa forma externa aos processos econômicos centrais, para se tornar um dos componentes essenciais da transformação social que vivemos. Será preciso lembrar que o principal setor econômico nos Estados Unidos, não é mais a indústria automobilística, ou bélica, mas a saúde, que representa $14 \%$ do seu PIB?

A questão que se coloca, e que analisamos neste artigo, é que enquanto as áreas produtivas dispôem de um sólido acúmulo teórico sobre a sua gestão - taylorismo, fordismo, toyotismo, TQM, Kanban etc. - a área social não dispõe dos paradigmas de gestão correspondentes, e fica oscilando entre burocratismos estatais ultrapassados, e privatizações desastrosas. Os serviços sociais são diferentes e necessitam de respostas especificas. A questão da gestão social tornou-se central.

PALAVRAS-CHAVE: gestão social, terceiro setor, ong, educação, saúde

* Ladislau Dowbor, 57, é doutor em Ciências Econômicas pela Escola Central de Planejamento e Estatística de Varsóvia, professor titular da PUC de São Paulo e da Universidade Metodista de São Paulo, e consultor de diversas agências das Nações Unidas. É autor de “A Reprodução Social”, editora Vozes 1998, e de numerosos trabalhos sobre planejamento econômico e social. Foi Secretário de Negócios Extraordinários da Prefeitura de São Paulo. Fone: (011) 3872-9877; FAX: (011) 3871-2911; E-mail ladislau(a)ppbr.com; home page http://ppbr.com/ld 


\section{UM NOVO CONTEXTO}

Já não é mais possivel vermos a sociedade como um sistema de interesses organizados em torno às atividades econômicas. $E$ foi a grande marca deste século que termina: a ordem era deixarmos as empresas tomar conta, pois assim teríamos investimentos, logo empregos, logo salários, e com isto pagaríamos o "resto".

O problema que enfrentamos é maior. O capitalismo como sistema é realmente um bom organizador micro-econômico da produção, mas é um péssimo distribuidor, um empregador cada vez mais precário, e um destruidor ambiental que leva, ao concentrar poderosas tecnologias em formas cada vez mais predatórias de exploração dos recursos naturais, a um impasse planetário. Não é aqui o lugar de elencar os dramas que se avolumam: não é à toa que tivemos, pela primeira vez na história da humanidade, e concentrados numa década, gigantecos foros mundiais para avaliar o esgotamento ambiental do planeta (Rio-92), o escândalo dos direitos humanos (Viena-93), a explosão demográfica (Cairo-94), os dramas sociais hoje insustentáveis (Copenhague-95), a tragédia da mulher presa na engrenagem das transformações econômicas e da desestruturação familiar (Beijing-95), o êxodo rural planetário que está gerando cidades explosivas no planeta (Istanbul-96).

Onde está a mão invisível? Ainda há quem afirme, com a tranqüilidade burra dos dogmáticos, que os problemas resultam do fato das nossas sociedades não serem suficientemente liberais. Na realidade, de mão invisível já estamos todos fartos. 0 Relatório sobre o Desenvolvimento Humano, das Nações Unidas, qualifica de obscenas as fortunas de pouco mais de quatrocentas pessoas no mundo, que dispõem de mais riqueza pessoal do que a metade mais pobre da humanidade. O relatório da Unctad, de 1997, traz uma análise precisa: nas últimas tres décadas, a concentração de renda aumentou dramaticamente no planeta, desequilibrando profundamente a relação entre lucros e salários. No entanto, estes lucros mais elevados não estão levando a maiores investimentos: cada vez mais, são desviados para atividades de intermediação especulativa, particularmente na área das finanças. O resultado prático é que temos mais injustiça econômica, e cada vez mais estagnação: a taxa de crescimento da economia do planeta baixou de uma média geral de $4 \%$ nos anos 1970 , para $3 \%$ nos anos 1980 , e $2 \%$ nos anos 1990. 
Esta articulação perversa é muito importante. Apesar de todos criticarmos as injustiças econômicas, ficava na nossa cabeça, formando um tipo de limbo semiconsciente, a visão de que afinal o luxo dos ricos bem ou mal se transformava em investimentos, logo em empresas, empregos e salários, que em última instância significariam mais bem estar. De certa forma, a desigualdade e os dramas sociais seriam um mal necessário de um processo no conjunto positivo e em última instância (e a longo prazo) gerador de prosperidade. É este tipo de "pacto" que está hoje desfeito. Na análise da Unctad, "é esta associação de aumento de lucros com investimento estagnado, desemprego crescente e salários em queda que constitui a verdadeira causa de preocupação"1.

Os atingidos não são apenas os pobres, mas todo o sistema produtivo. Um balanço do Le Monde Diplomatique nos mostra como a Peugeot, com 140 mil funcionários, ficou feliz com os lucros de $\mathbf{3 3 0}$ milhões de dólares conseguidos no primeiro semestre de 1998. Mas como se compara este resultado positivo com os lucros do setor de negociação de divisas do Citybank, onde 320 operadores geraram um lucro de 500 milhões de dólares no primeiro semestre de 1997? Entre as vantagens de ser especulador ou produtor, a dúvida já não existe. É interessante encontrar no Financial Times este comentário de Martin Wolf: “o que está em jogo, é a legitimidade da economia capitalista mundial"2.

O que está se tomando evidente, já não numa visão estreita de crítica sistemática anti-capitalista, mas de bom senso econômico e social, é que um sisțema que sabe produzir, mas não sabe distribuir, simplesmente não é suficiente. Sobretudo se, ainda por cima, joga milhões no desemprego, dilapida o meio-ambiente e remunera mais os especuladores do que os produtores. E a construção de alternativas envolve um leque de alianças sociais evidentemente mais amplo do que o conceito de classes redentoras, burguesa para uns, proletária para outros, que dominou o século $X X$. $O$ debate sobre quem tinha razão continuará sem dúvida a alimentar as nossas discussões, mas a realidade é que a própria realidade mudou. É significativo que a última cúpula mundial,

1 Rubens Ricúpero - Trade and Development Report 1997, Unctad, New York, Geneva 1997: "It is this association of increased profits with stagnant investment, rising unemployment and reduced pay that is the real cause of concern". (Overview, p. 11).

2 Dados mais amplos de comparação entre lucros produtivos e lucros especulativos podem ser encontrados no Le Monde Diplomatique, Novembre 1998. O artigo de Martin Wolf, Paises ricos terão de gjogar com as caratas da mesa, foi reproduzido na Gazeta Mercantil de 21 de setembro de 1998, p. A-16 
mais discreta do que as citadas acima, organizada pela Unctad (Lyon-98), já trabalhava o tema das parcerias para o desenvolvimento, reunindo formalmente governos, empresas e organizações da sociedade civil, na busca de novas articulações ${ }^{3}$.

\section{A ARTICULAÇÃO DO SOCIAL E DO PRODUTIVO}

A sociedade se tornou mais complexa. As atividades produtivas, sem dúvida, continuam essenciais, mas não contêm em si mesmas as condições do seu sucesso. Para que milhões de unidades empresariais da agricultura, da indústria, da construção, sejam produtivas, além da própria organização do tecido produtivo e do progresso da gestão empresarial, temos de nos dotar de sólidas infraestruturas de transporte, energia, telecomunicações, bem como água e saneamento, as chamadas "redes" de infraestruturas, sem as quais as empresas enfrentam custos externos insustentáveis e se tornam não-competitivas. Será demais lembrar que conseguimos encalacrar as cidades com transporte individual, o mais caro, desleixando o transporte coletivo que é dominante em qualquer país desenvolvido? Será inocente em termos de racionalidade da sociedade em seu conjunto o fato de termos optado por transporte rodoviário de carga, em vez do transporte ferroviário e por água? Quanto nos custa em gastos de saúde e desconforto o fato de uma ampla maioria de domicilios do país não terem acesso a um saneamento adequado?

O setor produtivo precisa portanto de infraestruturas adequadas para que a economia no seu conjunto funcione. Mas precisa também de um bom sistema de financiamento e de comercialização, para que os processos de trocas possam fluir de forma ágil: estes serviços de intermediação, no nosso caso, se tornaram um fim em si mesmo, drenando o essencial da riqueza do país, constituindo-se mais propriamente em atravessadores do que propriamente intermediários.

Finalmente, nem a área produtiva, nem as redes de infraestruturas, e nem os serviços de intermediação funcionarão de maneira adequada se não houver investimento no ser humano, na sua formação, na sua saúde, na sua cultura, no seu lazer, na sua

$3 \mathrm{Um}$ exemplo em nivel nacional, de novas orientações que se desenham, pode ser encontrado no texto de Emerson Kapaz, A importáncia do Pacto Politico (Folha de são Paulo, 22 de dezembro de 1998), ou nas declaração de Horácio Lafer Piva, da Fiesp, de que "a indústria de forma geral esta muito perplexa com o que anda acontecendo", ou ainda no surgimento de organizações de empresários progressistas como Cives, ou de preocupações humanitárias como Gilè e assim por diante. 
informação. Em outros termos, a dimensão social do desenvolvimento deixa de ser um "complemento", uma dimensão humanitária de certa forma externa aos processos econômicos centrais, para se tornar um dos componentes essenciais do conjunto da reprodução.

Não há nada de novo, naturalmente, em se afirmar que para o funcionamento adequado da área empresarial produtiva, são necessárias amplas redes de infraestruturas, serviços eficientes de intermediação, e um forte desenvolvimento da área social. O que há de novo é a compreensão de que o equilíbrio de desenvolvimento das várias áreas depende de articulações sociais mais complexas, que nos obrigam a deixar de lado as simplificações estatistas ou liberais.

\section{O SOCIAL: MEIO OU FIM?}

A familiaridade que temos com os conceitos de primário, secundário e terciário, ou de agricultura, indústria e serviços, tende a ofuscar uma mudança mais profunda, que é a mudança geral do peso específico do econômico e do social.

Quando pensamos nas locomotivas da economia vem-nos naturalmente à mente a indústria automobilística ou algo do gênero. Já não pensamos na agricultura, que emprega pouco mais de $2 \%$ de mão de obra nos países desenvolvidos. Mas a realidade é que a indústria segue, em termos de peso econômico, o mesmo caminho da agricultura, com algumas décadas de atraso ${ }^{4}$.

O principal setor econômico dos Estados Unidos é hoje a saúde, com 14\% do PIB. Mais ou menos no mesmo nível, está a chamada entertainment industry, a indústria do entretenimento, que pertence essencialmente à área cultural. A educação também assumiu, se somarmos a educação formal, a formação nas empresas, a explosão dos cursos de atualização tecnológica (da informática à inseminação artificial) e outros, dimensões que a tornaram um gigante tanto em termos de recursos envolvidos como de

\footnotetext{
4 Ainda que scja indiscutivel a queda do peso relativo da agricultura nas atividades econômicas, os $2 \%$ de emprego na área enganam: é que grande parte das atividades agrícolas tèm dimensões de indústria. e cada vez mais de serviços, como por exemplo os serviços de análise de solo, de inseminação artificial e assim por diante. Assim a agricultura utiliza um conjunto de atividades que passaram simplesmente a ser realizadas de forma diferente, ainda que servindo a produção rural.
} 
emprego. A saúde já não é mais um complemento onde pessoas com preocupações sociais vêm colocar um bandaid nas feridas das vítimas do progresso, como a cultura já não é o verniz chique de uma pessoa com dinheiro. A área social, hoje, é o negócio 5 .

A transformação é profunda. No decorrer de meio século, passamos de uma visão filantrópica, de generosidade assistencial, de caridade, de um tipo de bálsamo tranqüilizador para as consciências capitalistas, para a compreensão de que a área social se tornou essencial para as próprias atividades econômicås. Esta mudança profunda de enfoque foi positiva. As áreas empresariais, com suporte de numerosos estudos do Banco Mundial, passaram a entender que não se trata de simples cosmética social, mas das próprias condições indispensáveis para a produtividade empresarial. É a visão que leva, em numerosos países, a que as próprias empresas dêm forte sustento político ao ensino público universal, a sistemas de saúde abrangentes e eficientes e assim por diante.

Na última década, no entanto, estamos assistindo a uma nova transformação de enfoques, e mais profunda. Pensando bem, uma vida com saúde, educação, cultura, lazer, informação é exatamente o que queremos da vida. Em outros termos, o enfoque correto não é que devemos melhorar a educação porque as empresas irão funcionar melhor: a educação, o lazer, a saúde, constituem os objetivos últimos da sociedade, e não um mero instrumento de desenvolvimento empresarial. A atividade econômica é um meio, o bem-estar social é o fim.

\section{UMA ÁREA À PROCURA DO SEU PARADIGMA ORGANIZACIONAL}

As áreas sociais adquiriram esta importância apenas nos últimos anos. Ainda não se formou realmente uma cultura do setor. E a grande realidade, é que não sabemos como gerir estas novas áreas, pois os instrumentos de gestão correspondentes ainda estão engatinhando. Os paradigmas de gestão que herdamos - basta folhear qualquer revista de administração - têm todos sólidas raizes indústriais. Só se fala em taylorismo, fordismo, toyotismo, just-in-time e assim por diante. Como é que se faz um parto just-intime? Ou educação em cadeia de montagem? Um Cad-Cam cultural?

\footnotetext{
5 A emergência deste gigante foi também parcialmente disfarçada pelo generoso e vago conceito de serviços. Este conceito, que envolve desde a prostituta até o encanador, o governador e o consultor financeiro, merece ser arquivado. Tecnicamente, é um outros: tudo que não trabalha com a terra (primário) ou com máquina (secundário) adquire residualmente a etiqueta de serviços. Não podemos mais trabalhar com um outros que representa dois terços ou mais das nossas atividades econônicas.
} 
Seria relativamente simples considerarmos o social como sendo naturalmente de órbita do Estado. Aí, temos outros paradigmas da administração pública: Weber, a Prússia, as pirâmides de autoridade estatal. Há cada vez menos espaço para simplificações deste tipo. Como se atinge 165 milhões de habitantes a partir de uma cadeia de comando central? As áreas sociais são necessariamente capilares: a saúde deve atingir cada criança, cada familia, em condições extremamente diferenciadas. A gestão centralizada de mega-sistemas deste porte é viável?

Em termos práticos, sabemos que quando ultrapassamos 5 ou 6 níveis hierárquicos, os dirigentes vivem na ilusão de que alguém lá em baixo da hierarquia executa efetivamente os seus desejos, enquanto na base se imagina que alguém está realmente no comando. A agilidade e flexibilidade que exigem situações sociais muito diferenciadas não podem mais depender de intermináveis hierarquias estatais que paralizam as decisões e esgotam os recursos.

Na realidade, os paradigmas da gestão social ainda estão por ser definidos, ou construidos. É uma gigantesca área em termos econômicos, de primeira importância em termos políticos e sociais, mas com pontos de referência organizacionais ainda em elaboração.

O mundo do lucro já há tempos descobriu a nova mina de ouro que o social representa. Que pessoa recusará gastar todo o seu dinheiro, se se trata de salvar um filho? E que informação alternativa tem o paciente, se o médico the recomenda um tratamento? Hoje nos Estados Unidos um hospital está sendo processado porque pagava 100 dólares a qualquer médico que encaminhasse um paciente aos seus serviços. Paciente é mercadoria? A Nature mostra como dezenas de pesquisadores publicavam como cartas pessoais em revistas científicas opiniões favoráveis ao fumo: descobriu-se que recebem em média dez mil dólares das empresas de cigarros. Um cientista se defende, dizendo que esta é a sua opinião sincera, e porque não fazê-la render? Para regular a cultura, basta a cultura do dinheiro?

Empresas hoje fornecem software educacional para escolas, com publicidade já embutida, martelando a cabeça das crianças dentro da sala de aula. A televisão submete as nossas crianças (e nós) ao circo de quarta categoria que são os ratinhos de diversos tipos, explicando que está apenas seguindo as tendências do mercado, dando ao povo o que o povo gosta. Se o argumento é válido, porque um professor também não passar 
a ensinar o que os alunos gostam, sem preocupação com a verdade e o nível cultural? $\mathrm{Na}$ Índia hoje se encontram vilas com inúmeros jovens ostentando a cicatriz de um rim extraído: sólidas empresas de saúde de países desenvolvidos compram rins baratos no terceiro mundo para equipar cidadãos do primeiro. Aqui, as intermédicas geridas por empresas financeiras de seguro estão transformando a saúde em pesadelo. Qual é o limite?

No Brasil, a excessiva rigidez das tradicionais estruturas centralizadas do Estado e a trágica inadequação do setor privado na gestão do social têm levado a uma situação cada vez mais caótica. Uma avaliação recente não deixa dúvidas quanto à origem essencialmente institucional do estado caótico das políticas sociais no Brasil: "Ao longo das últimas décadas, o aparato institucional das políticas sociais pode ser caracterizado, em todos os níveis de poder, como um somatório desarticulado de instituições responsáveis por políticas setoriais extremamente segmentadas, que sobrepõem clientelas e competências, e pulverizam e desperdiçam os recursos, provenientes de uma diversidade desordenada de fontes. Isto redunda num sistema de proteção social altamente centralizado na esfera federal, ineficiente e iníquo, regido por um conjunto confuso e ambíguo de regulamentos e regras"6. Estamos falando de uma área cuja importância relativa no conjunto da reprodução social tende a se tornar central.

Em termos de recursos, é importante lembrar que o social, no Brasil, envolve, como ordem de grandeza, $25 \%$ do PIB do país ${ }^{7}$. O Brasil não é um país que gasta pouco com o social. Essencialmente, gasta mal. O apoio aos flagelados do Nordeste se transformou em indústria da seca, o complemento alimentar nas escolas em indústria da merenda, a saúde na indústria da doença, a educação está rapidamente caminhando para se tornar um tipo de indústria do diploma. A área social precisa hoje muito mais de uma reformulação político-administrativa do que propriamente de mais dinheiro.

\section{O SOCIAL: UM PODEROSO ARTICULADOR SOCIAL}

Um caminho renovado vem sendo construido através de parcerias envolvendo o setor estatal, organizações não-governamentais e empresas privadas. Surgem com força conceitos como responsabilidade social e ambiental do setor privado. $O$ chamado

6 Pnud/Ipea, 1996, p. 57

7 Banco Mundial, Brasil: Despesas do Setor Público com Programas de Assistência Social - Documentos do Banco Mundial, 27 de maio de 1998, vol. I - Os 25\% referem-se ao setor público e privado. 
terceiro-setor aparece como uma alternativa de organização que pode, ao se articular com o Estado e assegurar a participação cidadã, trazer respostas inovadoras. As empresas privadas ultrapassam a visão do assistencialismo, para assumir a responsabilidade que the confere o poder político efetivo que têm. Passa-se assim do simples marketing social, freqüentemente com objetivos cosméticos, para uma atitude construtiva onde o setor privado pode ajudar a construir o interesse público.

Onde funciona, como por exemplo no Canadá ou nos países escandinavos, a área social é gerida como bem público, de forma descentralizada e intensamente participativa. A razão é simples: o cidadão associado à gestão da saúde do seu bairro está interessado em não ficar doente, e está consciente de que trata da sua vida. Um pai não vai brincar com futuro dos seus filhos. De certa forma, o interesse direto do cidadão pode ser capitalizado para se desenhar uma forma desburocratizada e flexível de gestão social, apontando para novos paradigmas que ultrapassam tanto a pirâmide estatal como o vale-tudo do mercado 8 .

Outro eixo renovador surge com as políticas municipais, o chamado desenvolvimento local. A urbanização permite articular o social, o político e o econômico em políticas integradas e coerentes, a partir de ações de escala local, viabilizando - mas não garantindo, e isto é importante para entender o embate político - a participação direta do cidadão, e a articulação dos parceiros. $O$ surgimento de políticas inovadoras nesta área é muito impressionante. Peter Spink e um grupo de pesquisadores na Fundação Getúlio Vargas em São Paulo têm hoje um banco de 640 descrições de experiências exitosas. A Secretaria de Assuntos Institucionais do Partido dos Trabalhadores tem um banco de dados com 540 experiências. A Pólis publica excelentes resumos no quadro das Dicas Municipais. A Fundação Abrinq está ajudando a dinamizar um conjunto de atividades no quadro do movimento Prefeito-Criança. De Istanbul para cá, assistimos a uma aceleração de iniciativas locais que está transformando o contexto político da gestão social ${ }^{9}$.

$8 \mathrm{Um}$ bom resumo da organização da área social no Canadá pode ser encontrado no livro de Frank McGilly, Canada's Public Social Services, Oxford University Press, Toronto 1998

9 A título exemplo, ver o pequeno livro organizado por Peter Spink e Roberta Clemente, 20 Experiências de Gestão Pública e Cidadania, editado pela FGV em 1997; ou as experiências apresentadas no trabalho Herramientas Locales para Generar Empleo y Ocupación, coordenado por Maria Marcela Petrantonio, Mar del Plata, Mercociudades, 1998; Pólis editou um excelente número com 50 experiências de gestão, em 1996; a Fundação Abrinq publica um boletim informativo Prefeito Criança. 
O cruzamento entre a gestão social e a descentralização política oferece perspectivas particularmente interessantes.

Uma vantagem muito significativa das políticas locais é o fato de poderem integrar os diferentes setores, e articular os diversos atores. Um ponto de referência prático para esta visão pode ser encontrado nas atividades da Câmara Regional do Grande $A B C$, onde 7 municípios se articularam para dinamizar as atividades locais da indústria de plásticos: a formação dos trabalhadores é coordenada pelo sindicato dos químicos, em parceria com as empresas, Senai, Sebrae, empresas, faculdades e colégios locais, com apoio financeiro do FAT e outros que se articularam no processo. Programas de alfabetização como o Mova e de formação de jovens e adultos como o Seja criam um processo mais amplo de mobilização. O IPT aderiu ao projeto criando um sistema móvel de apoio tecnológico à pequena e média empresa (projeto Prumo). A Unicamp participou com a realização de um diagnóstico do setor plástico regional, e as pequenas e médias empresas se articulam por meio de reuniões periódicas da região. O conjunto das iniciativas, estas e outras, encontra a sua lógica e coerência através da Câmara Regional, que reune as administrações municipais da região, além de representantes de outras instâncias do governo e da sociedade civil. As diferenças do espectro político das prefeituras da região não impediram a articulação desta rede onde as diversas iniciativas — educação, emprego, renda, produção - se tornam sinérgicas em vez de dispersivas.

Não há fórmula universal na área social. Como demostra a riqueza do projeto médico de familia, por exemplo, a dimensão diferenciada de relações humanas é fundamental nas políticas sociais. Uma das mais significativas riquezas do desenvolvimento local, resulta justamente do fato de se poder adequar as ações às condições extremamente diferenciadas que as populações enfrentam.

Isto não implica, naturalmente, que as políticas sociais possam se resumir à ação local, às parcerias com o setor privado, e à dinâmica do terceiro setor. A reformulação atinge diretamente a forma como está concebida a política nacional nas diversas áreas de gestão social, colocando em questão a presente hierarquização das esferas de governo, e nos obriga a repensar o processo de domínio das macroestruturas privadas que dominam a indústria da saúde, os meios de informação, os instrumentos de cultura.

As tendências recentes da gestão social nos obrigam a repensar formas de organização social, a redefinir a relação entre o político, o econômico e o social, a 
desenvolver pesquisas cruzando as diversas disciplinas, a escutar de forma sistemática os atores estatais, empresariais e comunitários. Trata-se hoje, realmente, de um universo em construção.

\section{UM CENTRO DE REFERÊNCIA EM GESTÃO SOCIAL}

Não há dúvida que no Brasil a discussão ainda é muito recente, sobretudo se considerarmos que se trata de uma revisão profunda dos nossos paradigmas de como a sociedade se gere. Ainda estamos impregnados da visão de que a empresa só se interessa pelo lucro e será portanto inacessivel a uma visão social ou ambiental, de que organizar a participação da sociedade civil é apenas uma forma de desresponsabilizar o Estado e assim por diante.

É muito significativo constatarmos que uma série de conceitos básicos da reformulação política e social que está ocorrendo em muitos países sequer encontram tradução em português: é o caso de empowerment, que os hispano-americanos já traduzem de empoderamiento, no sentido de resgate do poder político pela sociedade; de stakeholder, ou seja, de ator social que tem um interesse numa determinada decisão; de advocacy, que representa o original etimológico de ad-vocare, de criar capacidade de voz e defesa a uma causa, a um grupo social; de accountability, ou seja, da responsabilização dos representantes da sociedade em termos de prestação de contas; de devolution, recuperação da capacidade política de decisão pelas comunidades, como contraposição ao conceito de privatização; trata-se também de entitlement, de self-reliance e tantos outros. Além do conceito chave de governance, que envolve capacidade de governo do conjunto dos atores sociais, públicos e privados, onde o conceito tradicional de governança, tal como existe no Aurélio, tem de ser reconstruído.

A articulação que temos pela frente envolve portanto uma aproximação articulada de empresários, de administradores públicos, de políticos, de organizações não governamentais, de sindicatos, de pesquisadores acadêmicos, de representantes comunitários. O potencial de um centro de referência em gestão social, que a PUC/IEE está dinamizando, mas que envolve participação equilibrada dos diversos segmentos sociais, resulta justamente do fato de abrir um espaço de arquitetura de decisões sociais, um entre outros, provavelmente com maior participação acadêmica neste caso, e maior preocupação com a dimensão de pesquisa, mas onde a palavra chave é justamente 0 conceito de articulação. 
É igualmente interessante a PUC-SP, como a FGV e a USP, terem criados centros de estudos do Terceiro Setor. É significativo a pós-graduação em Economia da PUC ter criado um Laboratório de Economia Social. De certa forma, se trata da superação de uma separação acadêmica tradicional no Brasil, onde Economia e Administração tratavam de como maximizar lucros, enquanto o Serviço Social tratava de encontrar muletas para as vítimas do processo. Hoje quem estuda gestão social se preocupa com as novas formas participativas de elaboração do orçamento, com um imposto de renda negativo (renda-mínima), com novas formas de representação política e o novo potencial da comunicação. A gestão social está buscando novos espaços em termos políticos, econômicos e administrativos. Não é mais um setor, é uma dimensão humana do próprio desenvolvimento, que envolve tanto o empresário como o pesquisador, ou o ativista do Movimento dos Sem Terra.

Os avanços não devem ser subestimados. A visão de uma política social de primeira dama, com cházinhos de caridade, data de ontem ainda, e ainda permeia grande parte da nossa sociedade. Na já mencionada cúpula das Nações Unidas Parceiros pelo Desenvolvimento, (Lyon-98), o representante de uma grande multinacional descrevia com entusiasmo as suas realizações em termos de oferecer melhores produtos para os clientes. Foi interrompido por uma senhora que the explicou que ele não tinha entendido o espírito da reunião: estava falando com pessoas, gente interessada nos impactos sociais, ambientais e econômicos dos diversos processos, e não apenas em encontrar, em clima de Papai Noel, presentes cheirosos e vistosos nas vitrines. Estava tratando com pessoas como ele, com cidadãos à procura de novas soluções, e não com clientes. A receptividade da interrupção foi impressionante. São mudançaçs profundas, de clima social, ou de cultura política, que dificilmente se colocam em números, mas que são muito reais.

Viemos de um século de grandes simplificações. Cansados da simplificação liberal, da qual herdamos 3,5 bilhões de habitantes do planeta que vivem com uma média de 350 dólares por ano, e não circulam na internet nem em espaço econômico algum, ou da simplificação estatista que buscou as soluções na mega-burocratização generalizada e no engessamento social através de leis e regulamentos, estamos buscando novos rumos. 


\section{REFERÊNCIAS BIBLIOGRÁFICAS}

BANCO MUNDIAL Brasil: despesas do setor público com programas de assistência social. Washington, 1998.

CINQUENTA experiências de gestão municipal. Polis ( $n^{\circ}$ esp.)

DOWBOR, L. A reprodução social. Petrópolis. Vozes, 1998.

FUNDAÇÃO ABRINQ Boletim Prefeito Criança. São Paulo, vários números.

KAPAZ, E. A importância do pacto político. Folha de São Paulo, 22 dez. 1998.

LE MONDE DIPLOMATIQUE Paris, Novembre 1998.

MCGILLY, F. Canada's public social services. Toronto. Oxford University Press, 1998.

PETRANTONIO, M.M. org. Herramientas locales para generar empleo y ocupación. Mar del Plata, Mercociudades, 1998.

PNUD/IPEA Relatório sobre o desenvolovimento humano no Brasil 1996. Brasilia, 1996.

SPINK, P \& CLEMENTE, R. Vinte experiências de Gestão Püblica e Cidadania. FGV, São Paulo, 1997.

UNCTAD Trade and development report 1997. New York. Unctad, 1997.

WOLF, M. Países ricos terão de jogar com as cartas na mesa. Gazeta Mercantil, 21 set 1998. p. A-16. 
SUMMARY: Capitalism is a good system when production is concerned, but not good enough a system if we want adequate distribution. And a system that produces well, but does not distribute accordingly, is structurally unbalanced. We need alternatives. What we have had up to now are not alternatives, but simplifications, with statism on one side, and liberalism on the other, redemption being expected to come either from the bourgeoisie or from the proletariat, depending on the political views. This debate will continue, but reality has changed.

Economic growth is obviously not sufficient, assuming it exists. No modern economic activity can be stimulated if we do not have the corresponding investment in people, through health, education, culture, leisure and so on. Social activities are no longer a complement to banking and industry. They have become central to the economy itself. In the U.S., the new economic locomotive is not the car industry, but health, representing $14 \%$ of GDP.

While social services have become central in modern economies, they still have to find their management paradigm. Huge, centralized state burocracies are not responsive enough, while privatization has led to dramatic abuse. The lack of specific management responses to the new demands of social services has become a key problem both in avanced and developing economies.

KEY WORDS: social management, third sector, non-profit management, education, health 